\title{
AUMENTO DA PRODUTIVIDADE DA LINHA DE DECAPAGEM E LAMINAÇÃO A FRIO DA ARCELORMITTAL VEGA*
}

Danilo Gonçalves de Oliveira ${ }^{1}$ Charles Pierri de Souza ${ }^{2}$ Rogério Martins Pereira ${ }^{3}$ Luciano Colzani ${ }^{4}$ Marcos Pimente/ ${ }^{5}$

\section{Resumo}

A linha de Decapagem e Laminação a Frio da ArcelorMlttal Vega vem recebendo constantes investimentos para aumento da sua capacidade produtiva sendo o mais recente a instalação do quarto tanque de decapagem química realizada em março de 2015. Para que esse investimento trouxesse o resultado esperado, eram esperadas melhorias de desempenho no processo de Laminação a Frio. O presente trabalho expõe a metodologia empregada para identificar os projetos necessários e os expressivos resultados obtidos com a sua condução ao longo do ano de 2014.

Palavras-chave: Laminação a frio; Produtividade; Desempenho; Investimentos.

\section{INCREASING THE PRODUCTIVITY AT ARCELORMITTAL'S PICKLING LINE AND TANDEM COLD MILL}

\section{Abstract}

ArcelorMittal's Pickling Line and Tandem Cold Mill is constantly receiving investments to increase its production capacity being the most recent of these the installation of the forth pickling tank in March 2015. In order to achieve the expected benefits of such investment, a performance improvement of the tandem cold mill would be necessary. This document exposes the methodology applied to identify the improvement projects and their solid results throughout 2014.

Keywords: Tandem cold mill; Productivity; Performance; Investments.

1 Eng. Eletricista, Especialista de Processo de Produção, Gerência de Operação de Decapagem e Laminação a Frio, ArcelorMittal Vega, São Francisco do Sul, SC, Brasil.

2 Tecnólogo em Gestão da Produção, Especialista de Processo de Produção, Gerência de Operação de Decapagem e Laminação a Frio, ArcelorMittal Vega, São Francisco do Sul, SC, Brasil.

3 Mestre em Eng. Elétrica, Especialista de Automação, Gerência de Manutenção de Decapagem e Laminação a Frio, ArcelorMittal Vega, São Francisco do Sul, SC, Brasil.

4 Mestre em Eng. Elétrica, Gerente de área, Gerência de Operação de Decapagem e Laminação a Frio, ArcelorMittal Vega, São Francisco do Sul, SC, Brasil.

5 Eng. Eletricist, Gerente de área, Gerência de Manutenção de Decapagem e Laminação a Frio, ArcelorMittal Vega, São Francisco do Sul, SC, Brasil. 


\section{INTRODUÇÃO}

A linha de Decapagem e Laminação a Frio da ArcelorMittal Vega, construída em 2003 com capacidade para 880.000 toneladas de aços planos por ano, vem recebendo constantes investimentos para o aumento da sua capacidade produtiva.

Em 2010 a capacidade instalada foi elevada para 1.440 .000 toneladas anuais com a instalação de tesoura rotativa e segunda enroladeira na saída do Laminador de Tiras a Frio (LAM). Já em Março de 2015 foi instalado o quarto tanque de decapagem ácida elevando sua capacidade para 1.600 .000 toneladas por ano.

Porém, para que o projeto de expansão realizado em 2015 atingisse o resultado esperado, identificou-se que o Laminador de Tiras a Frio, acoplado à linha de Decapagem, necessitava melhorar consideravelmente seu desempenho de produtividade e taxa de trabalho [1].

Para atingir esse objetivo, um grupo de trabalho foi designado para atuar com foco na produtividade. O mesmo tinha como atribuições o mapeamento das ações, quantificação do seu efeito no indicador chave e condução dos projetos necessários para atingir a meta estabelecida.

\section{METODOLOGIA}

Para permitir a quantificação dos ganhos de cada iniciativa mapeada e a correta gestão de recursos para priorizar as de maiores resultados, foi necessária, inicialmente, a criação de um modelo de velocidade.

Tal modelo deveria representar com fidelidade a capacidade produtiva da linha levando em consideração os limites atuais e os ganhos possíveis com a extrapolação dos mesmos.

Os limites de velocidade da linha de Decapagem e Laminação são os seguintes:

- Velocidade no processo de decapagem (velocidade máxima de $180 \mathrm{mpm}$ );

- Velocidade de saída do Laminador (limitada a 850mpm);

- Velocidade de entrada do Laminador (limitada a $210 \mathrm{mpm}$ );

- Limite de potência dos motores do Laminador (6000kW por cadeira).

O Modelo de Produtividade desenvolvido tem base estatística e apresentou resultados aderentes à condição normal de processo. Esse foi capaz de indicar com clareza que em $72 \%$ do material processado há uma diferença considerável na velocidade limite entre as linhas de Decapagem e a de Laminação a Frio, ou seja, em $28 \%$ dos casos as duas linhas estão com velocidades máximas muito próximas.

Entre as bobinas que o Laminador é a restrição, que representam $71,1 \%$ do total produzido, é possível indicar o motivo da restrição de produtividade em $78,4 \%$ dos casos e os detalhes são indicados na Figura 1. Já a linha de Decapagem representa $28,9 \%$ dos limites de velocidade. 


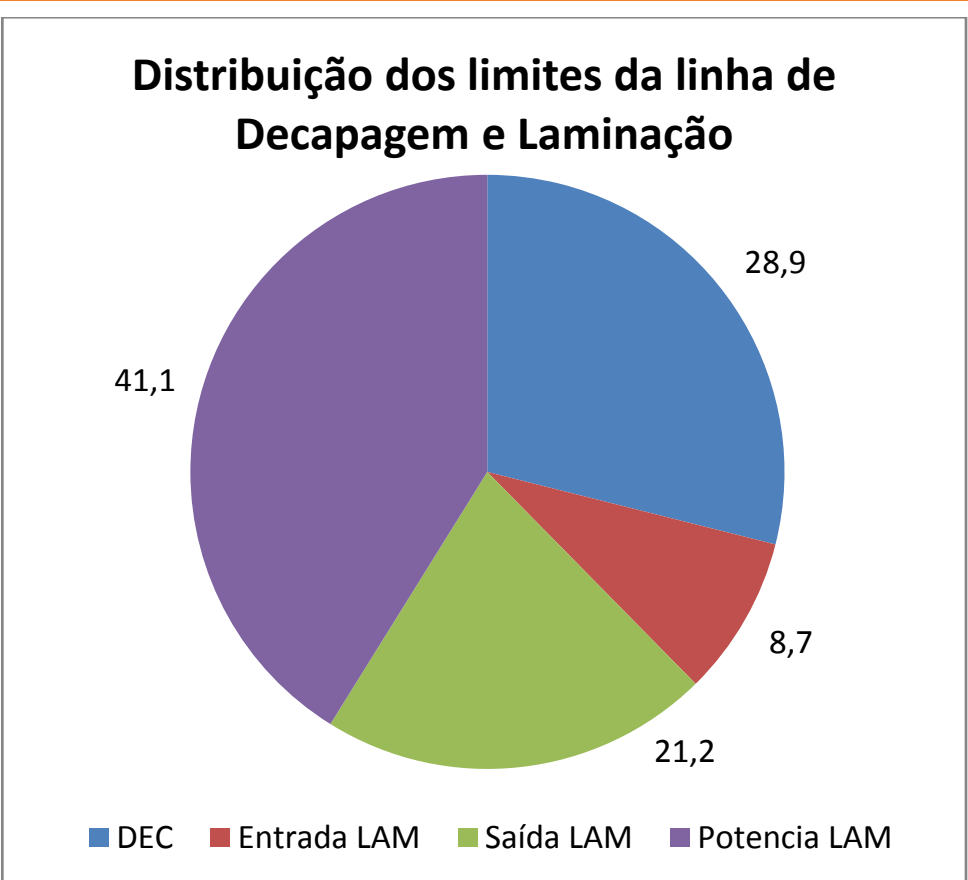

Figura 1: Distribuição dos limitantes de produtividade da linha de Decapagem e Laminação a Frio

Diante desses resultados, foram definidas três iniciativas macros para atuação:

- Velocidade de saída;

- Limites de potência dos motores principais do Laminador;

- Velocidade de seccionamento das bobinas.

\subsection{Velocidade de Saída}

Após o comissionamento da Linha de Galvanização II na ArcelorMittal Vega, com o foco no mercado de indústria, o volume de material de baixa espessura (menores que $0,50 \mathrm{~mm}$ ) produzido pela Linha de Decapagem e Laminação aumentou consideravelmente: de $3,5 \%$ para $19,1 \%$ ao mês. Essa evolução anual é mostrada na Figura 2.

A produtividade desses materiais, em razão da redução total, na faixa de $80 \%$, e baixa seção transversal e limite de escoamento, é fortemente dependente da velocidade máxima de saída do Laminador de Tiras a Frio, cujo limite atual é de 850mpm [2]. 


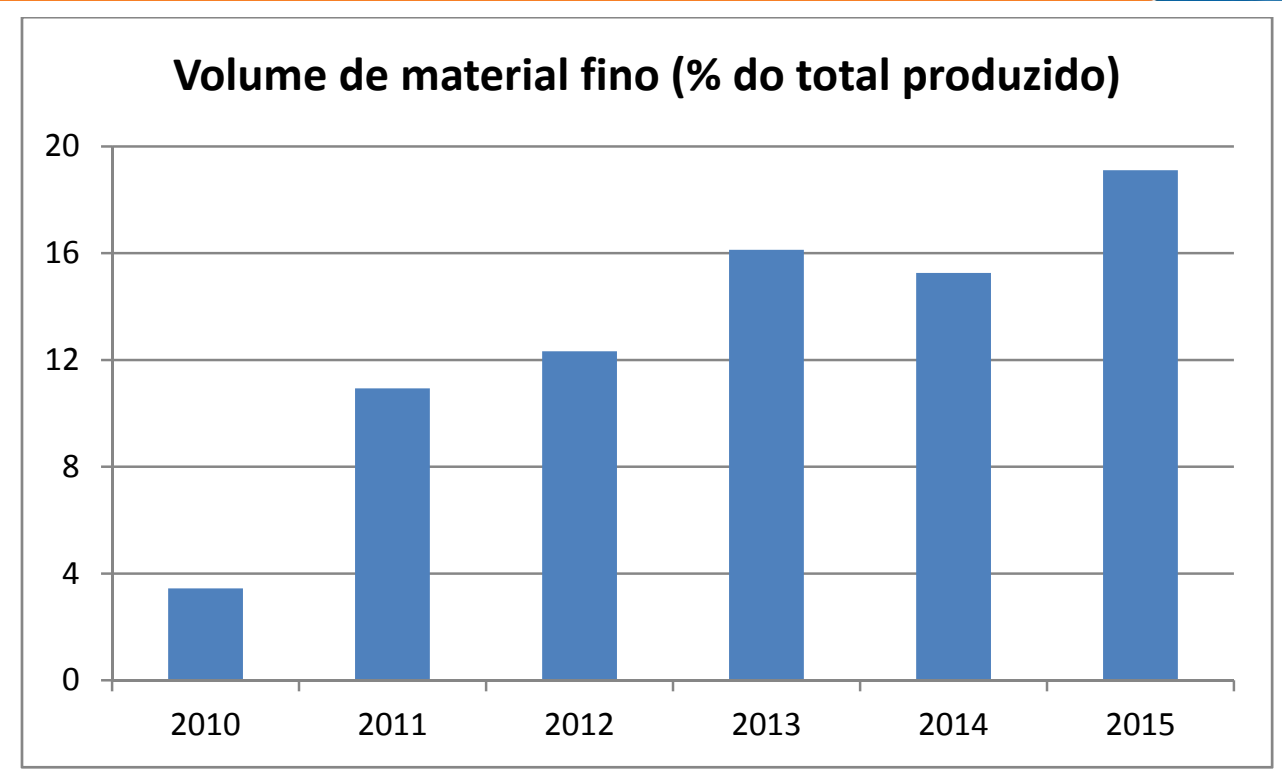

Figura 2: Volume de material com espessura de saída inferior a 0,50mm em relação ao total produzido

Para elevar, então, a produtividade desses materiais a principal alavanca de atuação é o aumento da velocidade máxima da linha, sendo identificado o novo limite de 900mpm como o necessário para o alcance do incremento de produção objetivado.

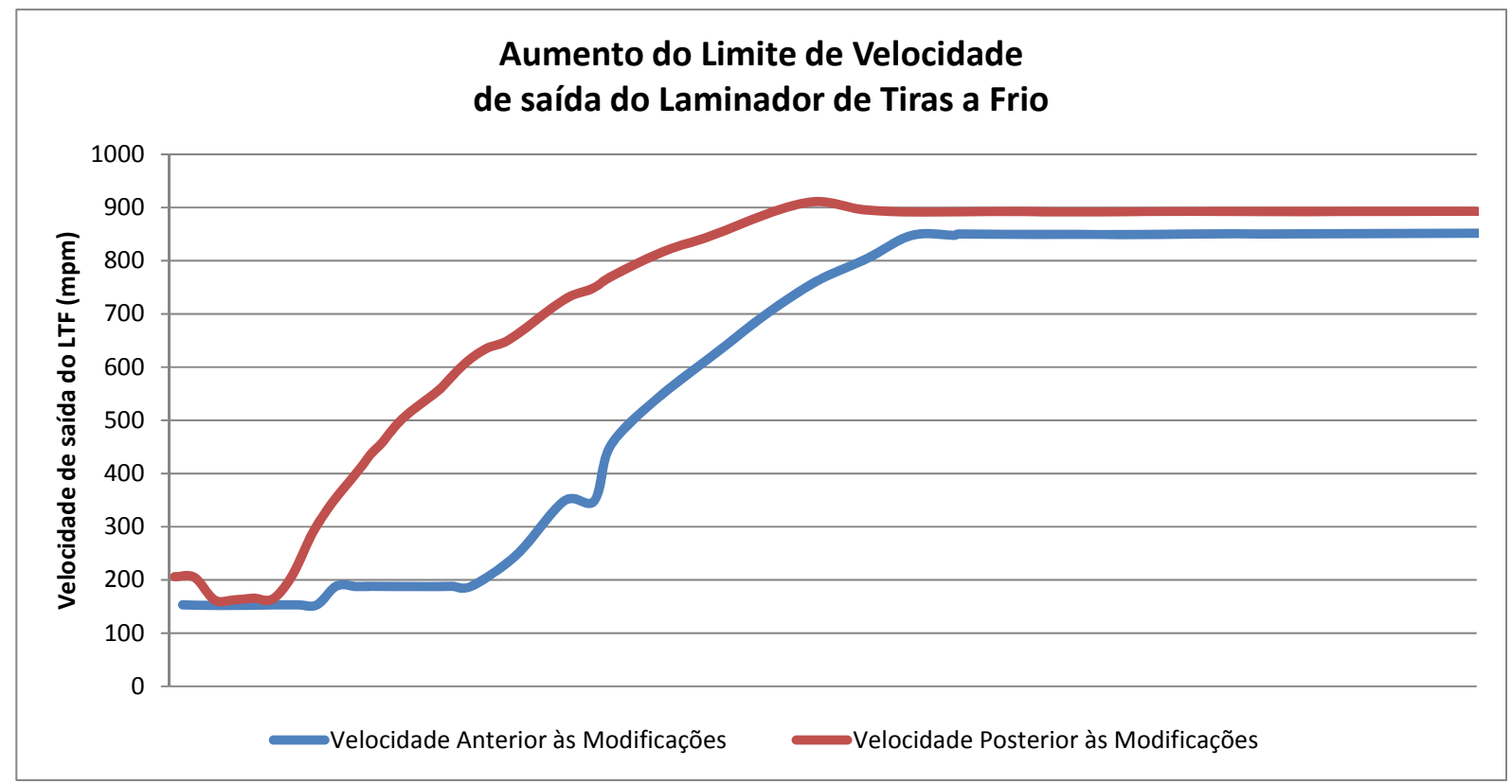

Figura 3: Elevação do limite de velocidade de saída do Laminador de Tiras a Frio

Para a condução do projeto foram verificadas as capacidades dos sistemas de acionamento dos rolos da seção de saída do Laminador. Esses itens foram verificados como capazes de atendimento ao aumento de velocidade em razão das melhorias realizadas ao longo dos últimos quatro anos no sistema de dissipação de energia de frenagem.

Além disso, foi observado que para alguns diâmetros de cilindros de trabalho o limite atingido poderia ser o de velocidade máxima dos motores principais do Laminador, especificamente na Cadeira 3. Como contenção foi modificada a distribuição de cilindros de trabalho de forma a garantir maiores diâmetros nessa cadeira e evitar essa região de trabalho. 


\subsection{Aumento da Utilização da Potência dos Motores Principais}

Ao longo dos últimos anos, o volume de materiais de elevada resistência mecânica está subindo constantemente em razão das exigências cada vez maiores para a produção de veículos mais seguros e ao mesmo tempo mais eficientes no consumo de combustível. Essa mudança no mercado tem impulsionado o desenvolvimento de novos produtos para atendimento dessas especificações em ritmo acelerado. A Figura 4 mostra a distribuição de aços dual-phase (DP) e de alta resistência com baixa liga (HSLA) ao longo dos anos.

Diante desse fato, a ArcelorMittal Vega está em fase de comissionamento de um terceiro pote de zinco para a Linha de Galvanização II, que terá como objetivo principal o atendimento dessa demanda do mercado por aços avançados de alta resistência, o que levará, ainda em 2015, a uma participação ainda mais expressiva desses aços no volume total a ser produzido.

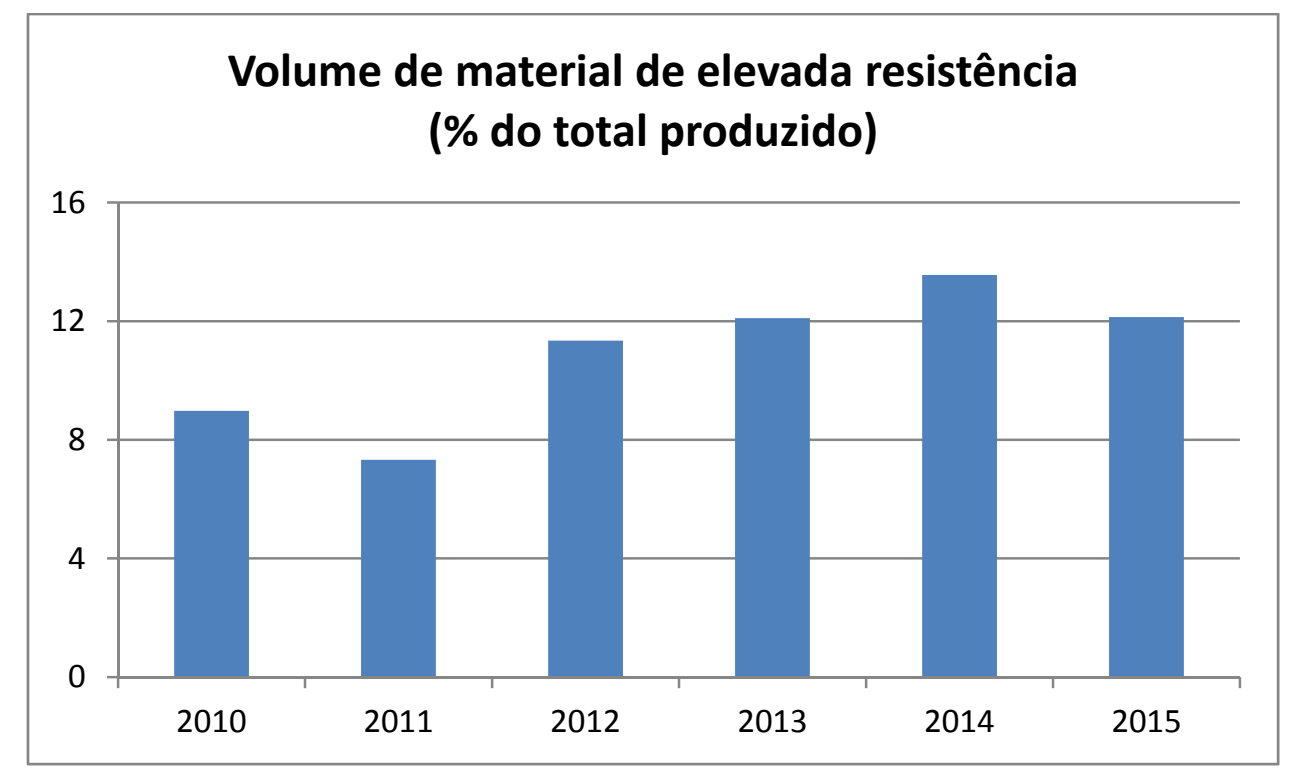

Figura 4: Volume de material de elevada resistência mecânica em relação ao total produzido

Aliada a essa mudança no mercado, a produção de materiais de elevada seção transversal também leva ao mesmo efeito quando analisadas as potências dos motores principais do Laminador de Tiras a Frio: torque elevado e, consequentemente, baixa velocidade de saída para permanecer dentro do limite de projeto definido em $6000 \mathrm{~kW}$ por cadeira [3].

A equipe do projeto identificou basicamente duas formas de atuação para elevar a produtividade nos materiais com elevado torque de laminação: diminuição da redução total do Laminador e/ou ajuste no sistema de acionamento dos motores principais da linha.

Tendo em vista os prazos definidos para a conclusão do projeto, o escopo de atuação e as limitações do Laminador de Tiras a Quente, a equipe do projeto decidiu-se então por não prosseguir com a primeira iniciativa neste momento para que seja analisada com mais rigor em outro trabalho mais abrangente.

Quanto aos ajustes possíveis no sistema de acionamento dos motores principais do Laminador de Tiras a Frio, foram identificados diversos parâmetros que poderia entregar o resultado desejado: maior velocidade de saída.

A equipe realizou extensa coleta de dados das informações referentes ao controle de velocidade dos motores principais, como taxa de aceleração, tempos de resposta 
e níveis de corrente, temperatura de motores e vibração do sistema mecânico de transmissão em cada caso.

Após extensa análise dos dados, avaliação de seus efeitos de longo prazo na vida útil dos motores e seus acionamentos, foram realizadas modificações nos ganhos das malhas de controles de velocidade.

Essas modificações tiveram como objetivo diminuir as ocorrências em que a potência máxima dos motores principais do Laminador é ultrapassada, o que leva a uma redução considerável da velocidade automaticamente pelo sistema de proteção. Ao evitar essa violação do limite de potência através da suavização da aceleração próximo da região crítica foi observado ser possível manter a velocidade em valores maiores, resultando em ganhos consideráveis de produção. A Figura 5 mostra a distribuição de velocidade e potência dos motores em duas bobinas similares processadas em condições diferentes: uma nas condições originais e outra após as modificações realizadas nas malhas de controle de velocidade.

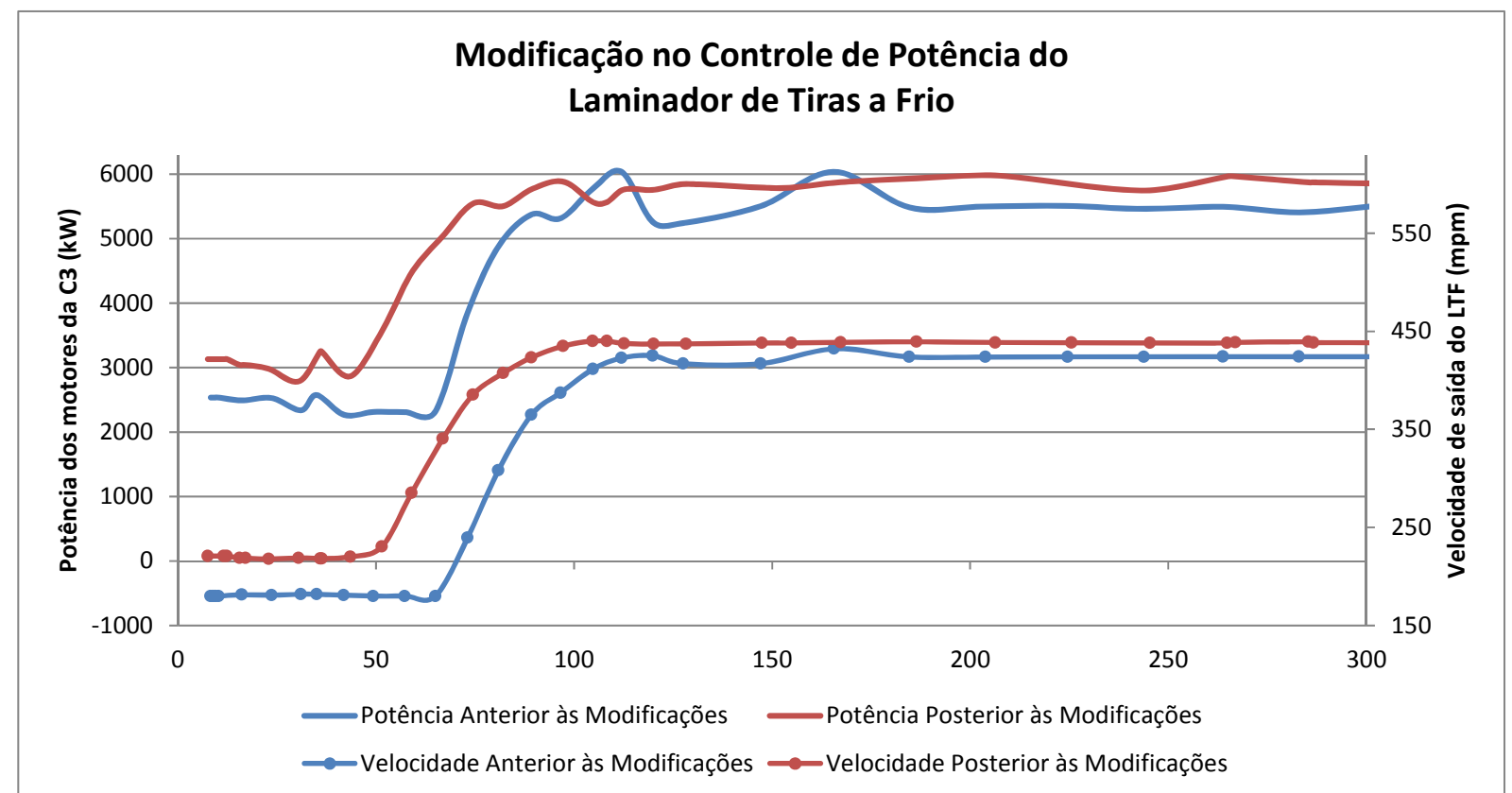

Figura 5: Efeito das modificações realizadas no controle de velocidade dos motores principais do Laminador de Tiras a Frio.

\subsection{Redução do Tempo da Sequência de Passagem de Solda}

Após a instalação da tesoura rotativa e da segunda enroladeira de bobinas na saída do Laminador de Tiras a Frio em 2010, a velocidade média de passagem da solda foi modificada dos anteriores $80 \mathrm{mpm}$, seguida de parada da linha para seccionamento da bobina e remoção da mesma do mandril, para $150 \mathrm{mpm}$, sendo o equipamento dimensionado para cortes a até $300 \mathrm{mpm}$ [4].

Essa limitação deve-se a diversos problemas encontrados durante a fase de comissionamento do equipamento, como interferências mecânicas e falhas nas sequencias de acionamento dos rolos, que levavam a erros de direcionamento da ponta da tira a altas velocidades resultando em colisão e embolamento da mesma com as estruturas da seção de saída.

Porém, diante da necessidade de elevação da capacidade de produção, e com a indicação pelo Modelo de Produtividade da possibilidade de ganhos expressivos com o aumento da velocidade de corte, fez-se necessário melhorar toda a sequencia 
de corte visando a redução das perdas para a realização do seccionamento das bobinas na saída do Laminador de Tiras a Frio.

A equipe de projeto realizou análise de todos os passos da sequencia, desde a redução de velocidade para início da passagem da solda até a finalização do corte e aumento final de velocidade.

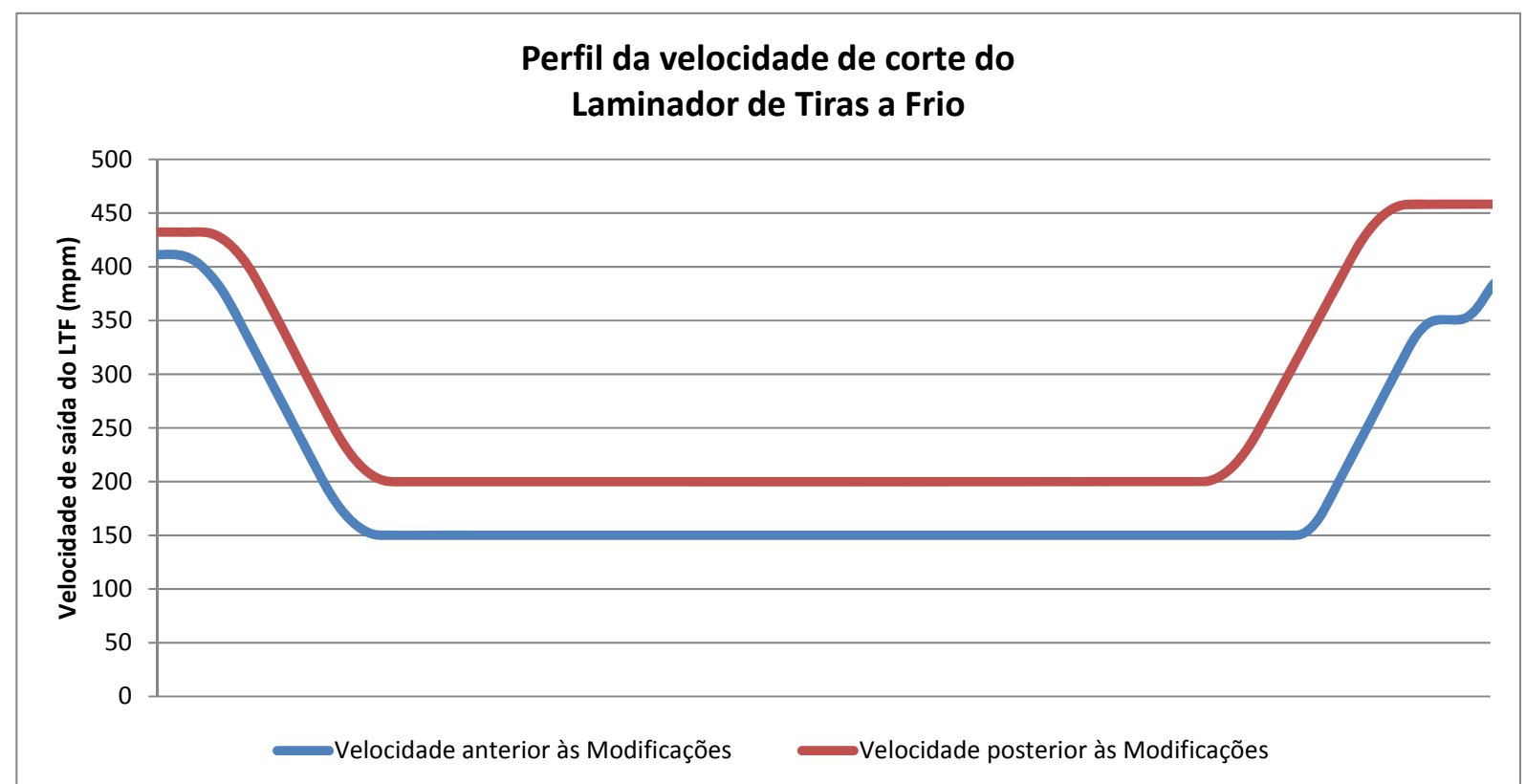

Figura 6: Efeito das modificações realizadas nas sequencia de passagem da solda no Laminador de Tiras a Frio

Foram realizadas modificações mecânicas nas mesas guias e adequações às lógicas de acionamento dos rolos de direcionamento durante a sequencia de passagem da solda para permitir seu funcionamento a altas velocidades além de ser possível a redução da metragem total necessária para a realização da sequencia.

Com isso foi possível modificar a velocidade de corte de $150 \mathrm{mpm}$ para $200 \mathrm{mpm}$ e reduzir a metragem para realização de toda a sequencia de 73 para $67 \mathrm{~m}$, conforme exemplificado na Figura 6, que compara duas bobinas processadas, sendo uma na condição original e outra após as modificações.

\section{RESULTADOS E DISCUSSÃO}

Os projetos conduzidos ao longo de 2014 para elevar a produtividade da linha de Decapagem e Laminação da ArcelorMittal Vega entregaram resultados expressivos e acima das expectativas iniciais.

O trabalho visando a elevação da velocidade máxima de saída do Laminador de Tiras a Frio resultou em disponibilidade extra de, em média, 8,05h de produção ao mês para a linha. Já o tempo da sequencia de passagem de solda foi reduzido em $4,56 \mathrm{~h}$ ao mês, enquanto que o projeto de aumento da utilização da potência dos motores principais resultou em 4,67h adicionais de produção mensal.

O resultado final dos projetos visando aumento de produtividade da linha de Decapagem e Laminação da ArcelorMittal Vega foi de cerca de 3,37\% em média para a condição anterior à instalação do quarto tanque de decapagem química, realizada em Março de 2015.

A capacidade produtiva anual foi elevada então das atuais $1,440,000$ toneladas para $1,493,000$ toneladas se mantidas as demais variáveis constantes. 
Tão importante que o aumento de produtividade foi garantir que o investimento realizado para elevar a produção para 1,600,000 toneladas ao ano atingirá o resultado previsto.

\section{REFERÊNCIAS}

1 ArcelorMittal Individual Investment File: Vega Light Project - ArcelorMittal FCA (January 2014)

2 Vega do Sul: Tandem Cold Mill functional description - Strip Control - ALSTOM 4MZB0152-E (Julho 2001).

3 Vega do Sul: Tandem Cold Mill Main Synchronous Motors Specification - SMS/DEMAG 4MKB0065-F (Fevereiro 2001).

4 Vega 2: Four Stands Tandem Cold Mill upgrade - Mill exit, Pinch rolls, Drum shear SMS/SIEMAG (Janeiro 2009). 